\title{
Praxisneuling
}

\section{Soll ich mich gegen Regresse versichern?}

Dr. med. P. Sch., Arzt für Allgemeinmedizin, Köln:

Ich bin erst seit zwei Jahren Vertragsarzt. In Kollegenkreisen höre ich immer wieder von drohenden Arzneimittel- oder Heilmittelregressen. Ist es hier sinnvoll, eine Regressschutzversicherung abzuschließen oder die Haftpflichtversicherung entsprechend mit einem Rechtsschutz zu erweitern?

Antwort: Eine Haftpflichtversicherung ist Pflicht. Wie bei KFZ-Versicherung kommen Sie an dieser schon aus berufsrechtlichen Gründen nicht vorbei. Weitere Versicherungen sind eine Frage des Charakters. Ich persönlich habe in über 30 Jahren Vertragsarztpraxis keinen Bedarf dafür gesehen, obgleich ich eine Regressforderung von seinerzeit über Hunderttausend D-Mark abwehren musste.

Grundsätzlich muss eine Regressschutzversicherung vorab abgeschlossen werden. Bekommen Sie heute eine Beratungsaufforderung aufgrund Ihrer Verordnungsweise, ist es für einen Abschluss zu spät. Des Weiteren kommt es auf die Höhe der versicherten Summe an. Ist der Regress höher als die Versicherungssumme, erhalten Sie nur die Höchstsumme und bleiben auf dem Rest sitzen. Vor allem: Die Versicherung hat kein Interesse an einer rechtlichen Auseinandersetzung. Sie wird die vereinbarte Maximalsumme zahlen und Ihnen den Versicherungsvertrag kündigen. Der nächste Vertrag wird aufgrund des Vorschadens, nach dem gefragt werden wird, umso teurer.

Verordnen Sie wirtschaftlich unter Beachtung der Arzneimittelrichtlinien und leitliniengerecht, sind Sie in der Regel in der Lage, Ihre Verordnungsweise rational zu begründen. Damit ist eine begründete Darlegung der

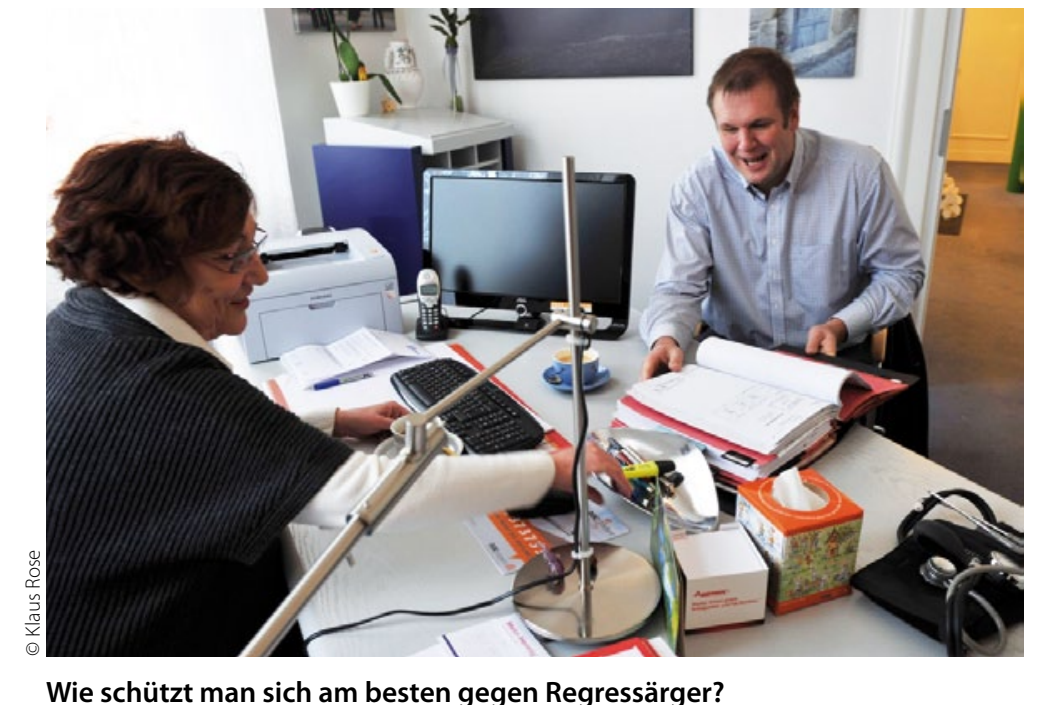

Überschreitung möglich und Sie können die Regressforderung erfolgreich abwehren. Dies gilt dann bei gleichbleibender Praxisstruktur auch für die Zukunft. Lassen Sie sich am Ende des Quartals eine Liste mit den zwanzig teuersten Verordnungsfällen ausdrucken. Überprüfen Sie diese Verordnungen auf Rationalität, Wirtschaftlichkeit und LeitlinienGerechtigkeit. Ist dies der Fall und ist dann die Überschreitung wieder im Streubereich, legen Sie die Liste entsprechend ab und gehen Sie unbesorgt Ihrer Praxis nach.

Seit einiger Zeit gibt es eine überlegenswerte Alternative zur Regressschutzversicherung: eine ProzessFinanzAG. Sie finanziert auch noch nach Eintreten des möglichen Schadensfalles die Lösung von außergerichtlichen Streitigkeiten ebenso wie Prozesse vor Gericht und Schiedsverfahren. Sie ist allerdings ebenfalls an einige Voraussetzungen geknüpft:

(1) Der zu finanzierende Anspruch beträgt mindestens 100000 Euro.
(2) Beim Anspruchsgegner ist eine ausreichende Bonität vorhanden.

(3) Es bestehen berechtigte Aussichten auf Erfolg vor Gericht.

Diese Prozessaussichten werden von FachRechtsanwälten vorab geprüft. Die Suche nach solchen Anwälten wird bereits von der ProzessFinanz AG unterstützt. Ergeben sich positive Erfolgsaussichten, werden sämtliche Kosten vom ersten Tag an vorfinanziert. Das macht die Entscheidung nicht nur einfacher, sondern macht den Arzt auch zu einem Prozessgegner auf Augenhöhe, denn oft scheitern auch Erfolg versprechende Verfahren am Prozesskostenrisiko, das in der ersten und zweiten Instanz bei 100000 Euro bereits an Gerichtskosten 23000 Euro ohne Rechtsanwalt etc. - ausmacht.

Der Haken? Wenn es denn einer ist, die ProzessFinanz AG erhält bei Erfolg vor Gericht oder Vergleich 30\% des Erlöses. 